\title{
Students' use of disability accommodations in emergency remote teaching
}

\author{
Erin Scanlon \\ Department of Physics, University of Connecticut - Avery Point, Groton, CT 06340 \\ Michael Vignal and Bethany R. Wilcox \\ Department of Physics, University of Colorado-Boulder, Boulder, CO 80309 \\ Jacquelyn J. Chini \\ Department of Physics, University of Central Florida, Orlando, FL 32816
}

\begin{abstract}
Disability is an often-overlooked aspect of diversity. Recent research has indicated that there are barriers to access and participation for disabled students inherent in the design of physics courses. To help counteract these barriers, universities are required to provide reasonable accommodations for disabled students. However, not all students use the accommodations they have access to because of social factors (e.g., disability stigma), and others do not have access to the professional diagnosis often required to access accommodations. The purpose of this study was to explore the experiences of students who identify with a disability/impairment who were taking an emergency remote teaching (ERT) physics course in Fall 2020 to inform policies about providing access to students in future remote and face-to-face courses. In this paper, we present the prevalence and types of impairments disabled students in physics courses reported, their reported accommodation usage, and ethical considerations of this work. Overall, we find that disabled students represent a sizeable group in physics courses, and there are positive and negative reasons students did not use or request accommodations.
\end{abstract}




\section{INTRODUCTION}

According to the National Science Foundation, disabled students [1-3] represent approximately $10-20 \%$ of all undergraduate science and engineering students [4]. The representation of different impairments has changed over time [4-7]. For example, the percent of all disabled students who identify with emotional/mental health and cognitive disorders (such as attention deficit hyperactivity disorder, ADHD) have increased by $30 \%$ and $20 \%$, respectively, from 1996 to 2012 while disabled students identifying with mobility, vision, and hearing impairments have decreased by $10-15 \%$ in the same time period $[5,8]$.

Even with the sizeable representation of disabled students in postsecondary STEM, research has shown that popular, research-based curricular materials are not designed with learner variation in mind [9]. There are also barriers in the structure of STEM courses, for example, distracting room layouts in SCALE-UP courses and lack of access to course materials outside of class [10-12]. Additionally, STEM faculty on average hold more negative beliefs about disability than their peers in other academic disciplines [1316]. To overcome barriers to access and full participation, instructors are legally mandated to provide course accommodations to students with documented disabilities [17-18]. However, not all students use their accommodations because of disability stigma (i.e., fear of negative evaluation by peers and instructors due to disability status) $[11,19]$ while other students do not have access to accommodations because of differential access to diagnoses (which intersects with income and race) [20].

Previous research has also indicated that practicing physicists have varied beliefs about providing accommodations. For example, some physics instructors said they would provide accommodations and use inclusive teaching strategies only for "students who need it," which can have different meanings including students who selfidentify as needing an accommodation, students who could provide a "valid excuse," and students whose learning would be significantly impacted by the instructional practice [21]. Instructors' beliefs about the necessity of providing accommodations may be additionally impacted with the shift to emergency remote teaching (ERT; i.e., the remote teaching format which resulted from the large-scale, unplanned transition of in-person courses to remote environments forced by the COVID-19 pandemic) as some believe ERT courses will be automatically more accessible and inclusive for all students due to the removal of the requirement of students' physical presence in the classroom and the ubiquity of lecture recordings [22-23]. However, the prevalence of students using accommodations, the types of accommodations requested, and disabled students' views about accommodations in the context of ERT have not been investigated and were the focus of this study. The purpose of this study was to explore the experiences of students who identify with a disability/impairment who were taking a physics course in Fall 2020, the first academic semester fully impacted by the COVID-19 pandemic, to inform policies about providing access to students in future remote and faceto-face courses.

\section{METHODS}

\section{A. Ethical considerations and limitations}

The design, data collection, and analysis for this study all occurred during the COVID-19 pandemic which has implications for ethical conduct of this research and limitations for the study [24]. Exploring the experiences of students in ERT courses starts from the assumption that universities should keep "progress as usual." Our sample includes institutions who chose to continue teaching and includes students who chose to continue to enroll. Some students likely did not enroll in Fall 2020 courses who would have enrolled if not for the pandemic, and these students' life experiences are likely different from the majority of students who continued taking courses. Additionally, our sample is primarily composed of participants from predominantly white institutions.

The survey was available to participants at the end of the Fall 2020 academic semester, which means some of the students who started the course may not have been invited to respond to the survey if they had already dropped/withdrawn from the course, either because of unmet needs or personal circumstances related to or not related to the pandemic. This implies that the data presented in this study do not reflect these students' experiences and we should not assume that all physics students will have similar experiences.

There is tension with sharing data from participants who were one of a very few who used a certain disability description or who were taking classes at a minority-serving institution. We do not want to erase the fact that this diversity exists, but we also do not want to overgeneralize from a few students' experiences.

There is also possible harm that could be done by this research. For example, readers should not overgeneralize beyond the individuals represented in this study (e.g., a practice worked for that person, why doesn't it work for you?). Also, we do not address the intersections between identities in this paper, and the findings may not hold for specific intersections of identities and/or student experiences. Portions of our findings could be interpreted as some disabled students benefited from the switch to ERT, and universities could use this justify online course offerings more broadly and for reasons not aligned with supporting students. As disability is not a monolith, we intend for these findings to be used to add student supports rather than to prescribe a "best" teaching modality. This study also should not be used to normalize using tax-payer money to fund research on teaching as part of a pandemic response, 
diverting money from directly impacting people's lives (e.g., healthcare, housing, food). Funding for this study was not tied to any pandemic-relief or response programs.

\section{B. Participant recruitment and data collection}

We recruited participants through an email solicitation sent to department chairs of about 570 institutions around the US. We offered an incentive for departments in the form of an aggregated breakdown of responses from participants from their department if we received more than 10 responses. We asked the department chairs to forward the solicitation to all students enrolled in a physics or related (e.g., astrophysics) course. The majority of participants were enrolled in an ERT course (only $2.1 \%$ of participants indicated they only had in-person course options), and we chose to include all complete responses in our analysis because all courses were likely modified during Fall 2020 due to the pandemic. Our goal for recruitment was to get a broad range of student responses. We intentionally tried to recruit participants from two-year colleges and minorityserving institutions (MSIs), and we offered MSIs an additional aggregate breakdown comparing their participants' responses to other MSIs. The survey was hosted in Qualtrics, which is Web Content Accessibility Guidelines (WCAG) Level AA compliant [25]. Participants were entered into a lottery for $50 \$ 20$ electronic gift cards.

\section{Survey and analysis}

The survey focused on the experiences of students enrolled in ERT courses in Fall 2020. In this study we focused on the experiences of participants who selfidentified as having a disability/impairment. In the survey, we used the term "disability/impairment" to solicit responses from a wide range of participants and to accommodate differences in preferred language. In this paper, we will shorten this to "disability" due to the constrained length. The survey questions pertaining to disability were about participants' disability identity (multiple-choice with an optional free response follow up question), their accommodations and usage in physics courses, their reasons for not using accommodations, a comparison of the impact of ERT and face-to-face on access to accommodations, and reasons for not having access to accommodations.

To analyze the participants' survey responses, we categorized the disability free responses by medical diagnoses [26] and by broader categories of impairment (i.e., physical/mobility, emotional/mental health, visual, hearing, health, and cognitive) from prior research [27]. Then, we examined accommodation usage by category of impairment.

\section{FINDINGS}

We received responses from participants taking courses at 94 different institutions. 64\% of the courses represented in the dataset were from departments that offer physics master's or PhD degrees, 27\% from departments that offer a bachelor's as the highest physics degree, and 9\% from departments that have an associate's, minor, or none as the highest physics degree. Additionally, $7.5 \%$ of the institutions are classified as Hispanic-Serving Institutions (HSIs), 2.5\% as Asian American Native American Pacific IslanderServing Institutions (AANAPISIs) and 0\% (i.e., responses from 2 participants) as Historically Black Colleges and Universities (HBCUs). This is unsurprising in the context of the disproportionate impact of the COVID-19 pandemic on communities of color. Of the institutions we sent the recruitment email to, only $34 \%$ were predominantly white institutions (PWIs), but participants from PWIs offering graduate degrees represent $58 \%$ of our sample.

The median time it took participants to complete the survey was 16.7 minutes. The survey link in the solicitation email was clicked 2,407 times. Of these, 258 clicks viewed less than $10 \%$ of the survey; a further 246 viewed $20 \%$ or less of the survey (i.e., the point of reporting what types of classes they had experienced), and 167 participants completed between $21-81 \%$ of the survey which indicates that most participants (79\%) completed the survey even though it was long. A total of 1,749 participants completed the full survey, and 39 were excluded from further analysis. Participants were excluded if they met multiple criteria including spending less than 5 minutes on the entire survey, selecting the same option for $90 \%$ or more of Likert-style questions in a section, nonsensical answers, or answering similar questions in opposing ways. A participant was never excluded for a single reason.

This yielded a total of 1,710 participants who reported on 1,919 courses. Regarding gender, $50.1 \%$ of participants identified as a woman, $45.1 \%$ as a man, $2.6 \%$ as non-binary or agender, $0.6 \%$ as another gender minority (in this case genderfluid or genderqueer, two-spirit, third gender, or questioning), and $1.6 \%$ preferred not to say. Additionally, $2.0 \%$ of participants identified as American Indian or Alaska Native, 22.7\% Asian, 3.7\% Black or African American, $10.8 \%$ Latina/o/x, 2.5\% Middle Eastern, 68.2\% White, $0.5 \%$ Native Hawaiian or Pacific Islander. 2\% (gender) and 13\% (race/ethnicity) of participants selected multiple options.

\section{A. Disability prevalence in ERT physics courses}

Overall, 16.2\% of all participants self-identified with a disability (where participants could select both impairment options) as shown in Table I. This is in agreement with recent NSF data which indicates $10-20 \%$ of undergraduate science and engineering students identify with a disability [4, 7].

In the survey, we invited participants to describe their disability in their own words with an optional free response question. Table II shows a summary of their coded responses. The most common category of impairment was cognitive impairments, which included: ADHD, which represented $4 \%$ of all participants and $48 \%$ of disabled participants who described their impairment(s); autism 
Table I: Participants self-identified disability

\begin{tabular}{lll}
\hline \hline Identify with: & $\begin{array}{l}\text { Student Level } \\
(\mathrm{N}=1,710)\end{array}$ & $\begin{array}{l}\text { Course Level } \\
(\mathrm{N}=1,919)\end{array}$ \\
\hline $\begin{array}{l}\text { Impairment that impacts } \\
\text { learning }\end{array}$ & $10.8 \%$ & $10.9 \%$ \\
$\begin{array}{l}\text { Impairment that doesn't } \\
\text { impact learning }\end{array}$ & $5.4 \%$ & $5.9 \%$ \\
$\begin{array}{l}\text { No impairment } \\
\text { Prefer not to answer }\end{array}$ & $78.5 \%$ & $77.8 \%$ \\
\hline
\end{tabular}

spectrum disorder, which represented $1 \%$ of all participants and $10 \%$ of described disabled participants; and specific learning disorder, which represented $1 \%$ of all participants and $13 \%$ of described disabled participants. The second most common category of impairment was emotional/mental health, which included anxiety (3\% of all participants and $31 \%$ of described disabled participants) and depression $(2 \%$ of all participants and $27 \%$ of described disabled participants). Health impairments were also common and included migraines $(0.5 \%$ of all participants and $5 \%$ of described disabled participants) and pain ( $0.5 \%$ of all participants and $5 \%$ of described disabled participants). This agrees with recent data showing that the proportion of disabled students who identify with mental health and cognitive impairments represent a meaningful fraction of students [4].

Many participants also identified with more than one disability. Of the 148 participants who described their disability in their own words, $39.2 \%$ identified with more than one disability. Common combinations of categories of impairment were emotional/mental health and cognitive impairments (1.3\% of all participants and $15.5 \%$ of disabled participants), cognitive and health impairments $(0.5 \%$ of all participants and $6.1 \%$ of disabled participants), and emotional/mental health and health impairments $(0.3 \%$ of all participants and $3.4 \%$ of disabled participants).

\section{B. Accommodation(s) usage}

In the survey, we also asked participants about their accommodations and how they use them in their physics courses (participants could select both of the "Yes, but..." options). Table III shows the percent of participants who received accommodations at their institution for their

Table II: Prevalence of categories of impairment in ERT physics courses. Some participants identified with multiple categories of impairment

\begin{tabular}{lll}
\hline \hline Category of Impairment & $\begin{array}{l}\text { \% of All } \\
\text { Participants } \\
(\mathrm{N}=1,710)\end{array}$ & $\begin{array}{l}\text { \% Disabled } \\
\text { Participants } \\
(\mathrm{N}=148)\end{array}$ \\
\hline Cognitive (C) & 5.3 & 61.5 \\
Emotional/Mental Health & 3.6 & 41.2 \\
(E/MH) & 1.5 & 17.6 \\
Health (Hl) & 0.2 & 2.0 \\
Hearing (Hr) & 0.1 & 1.4 \\
Physical/Mobility (P/M) & 0.1 & 1.4 \\
Visual (V) & & \\
\hline \hline
\end{tabular}

Table III: Percent of participants who receive accommodations at their institution for their disability(ies)

\begin{tabular}{lllllll}
\hline \hline & $\mathrm{P} / \mathrm{M}$ & $\mathrm{V}$ & $\mathrm{Hl}$ & $\mathrm{E} / \mathrm{MH}$ & $\mathrm{C}$ & $\mathrm{Hr}$ \\
\hline $\mathrm{N}$ & 4 & 2 & 32 & 74 & 109 & 4 \\
\hline $\begin{array}{l}\text { Yes } \\
\begin{array}{l}\text { Yes, but only for } \\
\text { some of my } \\
\text { disabilities }\end{array}\end{array}$ & 100 & 50 & 46.9 & 32.4 & 27.5 & 50 \\
$\begin{array}{l}\text { Yes, but I do not } \\
\text { use them }\end{array}$ & 0 & 0 & 12.5 & 5.4 & 11.9 & 25 \\
No & 0 & 50 & 25.0 & 55.4 & 55.0 & 0 \\
\hline \hline
\end{tabular}

P/M: physical/mobility, V: visual, Hl: health, E/MH: emotional mental health, C: cognitive, Hr: hearing

disability(ies) disaggregated by category of impairment. Accommodation use varied both across and within categories; only the physical/mobility and hearing categories, four students each, had all students report using accommodations. Additionally, the emotional/mental health and cognitive categories of impairment (74 and 109 participants) had less than $50 \%$ of participants report using accommodations.

All participants were invited to describe their accommodations in their own words. Of the 46 participants who described their accommodations for multiple courses (52 unique responses), commonly cited accommodations were extended test time ( 39 responses), flexible deadlines (7), extra time on assessments (5), flexible attendance (3), closed captioning (3), and quiet test environment (3).

\section{Accommodations and meeting needs}

In the survey, we asked participants if their accommodation(s) met their needs to help them learn in their physics course(s), shown in Table IV. Only participants within the health, emotional/mental health, and cognitive categories of impairment strongly disagree that their accommodation(s) met their needs. These are also the categories of impairment that represented the largest proportion of disabled students in this study.

\section{Lack of accommodation(s)}

We also asked participants who reported that they did not receive accommodation(s) about the reason they did not receive accommodations. Table $\mathrm{V}$ shows the percent of participants who cited reasons for not receiving accommodations in a multi-select question. There were no participants with a physical/mobility impairment and only one with a visual impairment who answered this question.

Table IV: Percent of participants whose accommodation(s) met their needs in their ERT physics course

\begin{tabular}{lllllll}
\hline \hline & $\mathrm{P} / \mathrm{M}$ & $\mathrm{V}$ & $\mathrm{Hl}$ & $\mathrm{E} / \mathrm{MH}$ & $\mathrm{C}$ & $\mathrm{Hr}$ \\
\hline $\mathrm{N}$ & 4 & 1 & 15 & 23 & 34 & 3 \\
\hline Strongly Agree & 0 & 100 & 33.3 & 34.8 & 38.2 & 66.7 \\
Agree & 100 & 0 & 40.0 & 47.8 & 38.2 & 0 \\
Disagree & 0 & 0 & 6.7 & 8.7 & 14.7 & 33.3 \\
Strongly Disagree & 0 & 0 & 20.0 & 8.7 & 8.8 & 0 \\
\hline \hline
\end{tabular}


Table V: Percent of participants' reasons for not receiving accommodation(s) in ERT physics courses

\begin{tabular}{llll}
\hline \hline $\mathrm{N}$ & $\mathrm{H}$ & $\mathrm{E} / \mathrm{MH}$ & $\mathrm{C}$ \\
\hline $\begin{array}{l}\text { I have not asked for } \\
\text { accommodations }\end{array}$ & 53.8 & 47.3 & 39.7 \\
$\begin{array}{l}\text { I feel my accommodations give me } \\
\text { an unfair advantage }\end{array}$ & 7.7 & 6.8 & 6.9 \\
$\begin{array}{l}\text { I do not want others to know about } \\
\text { my disabilities }\end{array}$ & 15.4 & 17.6 & 13.8 \\
$\begin{array}{l}\text { I do not have a diagnosis from a } \\
\text { physician }\end{array}$ & 15.4 & 6.8 & 13.8 \\
$\begin{array}{l}\text { I feel there are too many barriers to } \\
\text { accessing accommodations }\end{array}$ & 0 & 14.9 & 10.3 \\
$\begin{array}{l}\text { My institution is unable to grant my } \\
\text { accommodations }\end{array}$ & 0 & 0 & 3.4 \\
\begin{tabular}{l} 
The reason is not listed \\
\hline \hline
\end{tabular}
\end{tabular}

Again, students with health, emotional/mental health, and cognitive impairments most frequently stated they did not receive accommodations. One participant said: "I have accommodations for my migraines to extend deadlines on short notice. I have encountered many people that believe I'm just faking it to not do my work, so I don't like talking about it unless it is absolutely necessary." Another participant said: "I probably could have received accommodation for the exam, which would help, but it takes effort for me to ask and [I] feel stigmatized." Another participant expanded upon their response choice "I feel my accommodations give me an unfair advantage" by saying: "I don't want to use the accommodations when I don't feel I need them. To be honest, I'd rather just take a zero than use my accommodations."

Other students had more positive reasons for not receiving accommodations. For example, a different participant said: "I didn't activate that accommodation for this class for this quarter because I can get the same results just by asking and not having our [institution's disability accommodation office] strong-arm the instructor." Other participants said they had take-home exams which provided them with enough time and that pre-recorded lectures allowed them to pause and re-watch as needed.

Across the survey, participants cited similar reasons for either not using their accommodation(s) or for having a lack of accommodation(s). For example, participants cited not wanting others to know about their disability, lack of medical diagnosis, and institutional barriers to accessing accommodations as reasons for both not requesting and for not using accommodations in their physics courses. One participant commented on the timing of receiving a medical diagnosis and accommodations: "My accommodations were provisional, as I just got the test results this week. Most of the semester I struggled to do my work, and the accommodations were too little too late." These issues should be a focus for instructors and administrators, as they may be a two-stage barrier for students. This implies that some participants do not have access to and/or inclusion in physics courses because they are stopped from requesting accommodations while others do not use them.

\section{DISCUSSION AND IMPLICATIONS}

Our findings align with national data in showing that disabled students are in physics courses and represent approximately $16 \%$ of all students. If instructors are not aware of disabled students, it is not because they are not there. Additionally, our findings indicate many students do not request accommodations because they do not want to disclose their disability and/or diagnosis to instructors. Therefore, instructors should design their courses to support a wide range of students without needing to know students' individual needs. The Universal Design for Learning framework provides [28] ideas for the proactive design of learning environments to support learner variation [29].

Many participants indicated that they do not request or use accommodations because they feel the accommodations will give them an "unfair advantage." These findings highlight the need for instructors to emphasize and communicate to students that accommodations are fair and are a tool to be used to provide access and supports that were included in the course for non-disabled students. This communication should be done proactively because if students do not request accommodations, then the instructor will not know that there are students with unmet needs, contributing to the invisibility of disability in physics.

Multiple students in our study cited disability stigma as a reason for not requesting and/or using accommodations. If a student is requesting an accommodation, they need it to fully access and be included in a course. It is typically a long, complicated process to receive accommodations at the postsecondary level. We need to believe students. Instructors should create a classroom culture that values learner variation, talk about the value of disability in physics, and describe why accommodations are fair and important to push back on the ableist views that pervade our society.

From a research perspective, we see different responses across impairment categories. If we had created our survey with only binary (i.e., yes or no) disability status questions, we would not have been able to see interactions with categories of impairment. This supports the recommendation that education researchers should collect richer data than binary disability status and should allow participants to describe their disability(ies) in their own words. Disabled students represent a sizeable group of students in physics. In general, there is more research required about their experiences in physics courses and in the broader physics community to build an inclusive culture.

\section{ACKNOWLEDGMENTS}

This work was supported by the CU-Boulder Department of Physics and NSF HRD 1750515. Thank you to the participants who completed the survey during this wild time. 
[1] Some people prefer person-first language (e.g., "students with disabilities," "person with visual impairment," or "scientists with a disability") because it emphasizes the person over the ability. However, others feel impairment-first language can highlight the social aspect of disability (e.g., inaccessible curricula create disabled students) and that the difference is an integrated part of the person's identity (e.g., Autistic person or Deaf person, just as we would typically say "tall person" rather than "person with tallness"). While there are trends in specific communities, there is not a single, universally accepted language related to disability. When you are talking with an individual, it is best practice to ask them about their preferred language. See refs [2] and [3] for additional information.

[2] J. O. Bickford, Preferences of Individuals with Visual Impairments for the Use of Person-First Language, RE:view 36, $120(2004)$.

[3] C. Liebowitz, I am Disabled: On Identity-First Versus PeopleFirst Language, The Body is Not an Apology blog (2015).

[4] National Science Foundation, National Center for Science and Engineering Statistics, Women, Minorities, and Persons with Disabilities in Science and Engineering: 2019. Special Report NSF 19-304, (2019).

[5] G. A. Scott, Higher education and disability: Education needs a coordinated approach to improve its assistance to schools in supporting students, Government Accountability Office, 10,1 (2009).

[6] K. Raue, and L. Lewis, Students with Disabilities at DegreeGranting Postsecondary Institutions. First Look. NCES 2011018. National Center for Education Statistics, (2011).

[7] National Center for Science and Engineering Statistics, Women, minorities, and persons with disabilities in science and engineering: 2015 (Special Report NSF 15-311). Arlington, VA, (2015).

[8] National Center for Education Statistics, 1995-96 national postsecondary student aid study: 1996. Report NPSAS:96, (1996).

[9] E. Scanlon, J. Schreffler, W. James, E. Vasquez, and J. J. Chini, Postsecondary physics curricula and Universal Design for Learning: Planning for diverse learners, Phys. Rev. Phys. Educ. Res. 14, $020101 \quad$ (2018). doi: 10.1103/PhysRevPhysEducRes.14.020101.

[10] W. James, K. Lamons, R. Spilka, C. Bustamante, E. M. Scanlon, and J. J. Chini, Hidden walls: STEM course barriers identified by students with disabilities, 2019 PERC Proceedings [Provo, UT, July 24-25, 2019], edited by Y. Cao, S. Wolf, and M. B. Bennett, doi:10.1119/perc.2019.pr.James. doi: 10.1119/perc.2019.pr.James

[11] W. James, C. Bustamante, K. Lamons, E. Scanlon, and J. J. Chini, Disabling barriers experienced by students with disabilities in postsecondary introductory physics, PRPER 16, 02011 (2020). doi: 10.1103/PhysRevPhysEducRes.16.020111

[12] A. Lannan, E. Scanlon, and J. J. Chini, 2021, Resources for supporting students with and without disabilities in your physics courses, TPT 59, 192 (2021). doi: 10.1119/10.0003662

[13] S. Rao, Faculty attitudes and students with disabilities in higher education: A literature review, Coll. Stud. J 38, 191 (2004).

[14] E. Schoen, M. Usyal, and C. D. McDonald, Attitudes of faculty members toward treatment of disabled students reexamined, Coll. Stud. J. 21, 190 (1986).
[15] M. L. Lewis, Faculty attitudes toward persons with disabilities and faculty Attitudes toward to accommodate students with learning disabilities in the classroom, Dissertation, Auburn University (1998).

[16] M. E. Skinner, Faculty willingness to provide accommodations and course alternatives to postsecondary students with learning disabilities. International Journal of Special Education 22, 32 $\underline{(2007)}$

[17] ADA: Americans with Disabilities Act of 1990, 42 U.S.C. $\$$ 12101 et seq. (2009).

[18] United States, Rehabilitation Act, 1998.

[19] J. Trammell, Postsecondary students and disability stigma: Development of the postsecondary student survey of disabilityrelated stigma (PSSDS), J. Postsecondary Educ. Disability. 22 $106(2009)$.

[20] S. A. Annamma, B. A. Ferri, and D. J. Connor, Disability critical race theory: Exploring the intersectional lineage, emergence, and potential futures of DisCrit in education. Review of Research in Education 42, 46 (2018). doi: 10.3102/0091732X18759041

[21] E. M. Scanlon and J. J. Chini, Physics instructors' views about supporting learner variation: Modifying the Inclusive Teaching Strategies Inventory, 2019 PERC Proceedings [Provo, UT, July 24-25, 2019], edited by Y. Cao, S. Wolf, and M. B. Bennett, doi: 10.1119/perc.2019.pr.Scanlon.

[22] S. Puang, As colleges strive for a return to normal, students with disabilities say, 'no thanks': Pandemic necessity showed the universal benefits of learning accommodations. Is there any going back?, The Chronicle of Higher Education (2021).

[23] L. Burke, 'Proof of concept': Some students with disabilities asked for recorded lectures before the pandemic. With universities eyeing reopening, will they take that flexibility away?, Inside Higher Ed (2021).

[24] Our considerations of the ethics of this research has been deepened by conversations with colleagues in the physics education research community. We believe that there should be more explicit conversations around ethics in research and the stakes have been brought into focus during the COVID-19 pandemic.

[25] World Wide Web Consortium, Understanding conformance (2016).

[26] American Psychiatric Association, Diagnostic and statistical manual of mental disorders (DSM-5). American Psychiatric Pub (2013).

[27] E. M. Scanlon and J. J. Chini, Ability profiles: A framework for conceptualizing dimensions of ability, 2018 PERC Proceedings [Washington, DC, August 1-2, 2018], edited by A. Traxler, Y. Cao, and S. Wolf, DOI: 10.1119/perc.2018.pr.Scanlon.

[28] CAST, Universal Design for Learning Guidelines version 2.0. Wakefield, MA: Author (2011).

[29] J. J. Chini and E. Scanlon, Designing for difference: Conceptualizing and planning for variations in learners' needs, abilities, and interests, AAAS IUSE blog (2021). 